\title{
PROPOSTA DE PLUVIÔMETRO DE BAIXO CUSTO UTILIZANDO A PLATAFORMA DE PROTOTIPAGEM ARDUINO
}

\author{
Rafael Grecco Sanches ${ }^{\text {(a) }}$,Maurício Sanches Duarte Silva ${ }^{(b)}$, Bruno César dos Santos ${ }^{(c)}$, \\ Diego Narciso Buarque Pereira ${ }^{(d)}$
}

(a) Laboratório de Climatologia e Conforto Térmico, Centro de Recursos Hídrico e Educação Ambiental (CRHEA), Escola de Engenharia de São Carlos (EESC), Universidade de São Paulo (USP).Email: rafagsanches@usp.br

(b) Laboratório de Climatologia e Conforto Térmico, Centro de Recursos Hídrico e Educação Ambiental (CRHEA), Escola de Engenharia de São Carlos (EESC), Universidade de São Paulo (USP).Email:mauriciosanches@usp.br

(c) Laboratório de Climatologia e Conforto Térmico, Centro de Recursos Hídrico e Educação Ambiental (CRHEA), Escola de Engenharia de São Carlos (EESC), Universidade de São Paulo (USP).Email: diego.narciso@usp.br

(d) Laboratório de Climatologia e Conforto Térmico, Centro de Recursos Hídrico e Educação Ambiental (CRHEA), Escola de Engenharia de São Carlos (EESC), Universidade de São Paulo (USP).Email:brunounifal@hotmail.com

Eixo: Climatologia em diferentes Níveis Escalares: Mudanças e Variabilidade

\section{Resumo}

\begin{abstract}
A aquisição de dados climáticos são de extrema necessidade para compreensão do meio ambiente, sendo fundamental em diversas atividades humanas. Um dos problemas é o alto custo destes equipamentos.Otrabalho objetivou desenvolver um protótipo de pluviômetro de baixo custo utilizando a plataforma Arduino e realizar a validação e eficiênciados registros em relação adados referência. Para tanto selecionou-se um período de 10 dias de observação. Aplicou-se métodos estatísticos de correlação linear,a fim de verificar a consistência dos dados pluviométricos do protótipo em relação aos de uma estação convencional e uma automática.Os resultados foram satisfatórios uma vez que os dados do protótipo mostrou-se homogêneo em relação aos pluviômetros de referências $\left(r=0,96\right.$ e $\mathrm{R}^{2}=0,95$ para a convencional; $r=0,97$ e $\mathrm{R}^{2}=0,93$ para a automática). Portanto o pluviômetro de baixo custo pode ser considerado confiável.
\end{abstract}

Palavras chave: Climatologia, Meteorologia, Pluviometria, Pluviômetro,Arduino;

\section{Introdução e Justificativa}

A interpretação e compreensão do clima e do tempo e sua repercussão no espaço geográfico tem sido tema constante de discussões em nossa sociedade nos últimos anos, principalmente pelo fato de desconhecermos todos os fatores que realmente influenciam na dinâmica atmosférica do nosso planeta, às vezes com duração temporal muito superior à nossa existência terrena. Atualmente, com os avanços tecnológicos surgidos pós meiotécnicocientífico-informacional é vasto o número de recursos tecnológicos disponíveis que podem ser utilizados nos estudos e pesquisas nas diversas áreas da ciência e a Climatologia Geográfica se inclui nessa realidade. 
XVII Simpósio Brasileiro

de Geografia Fisica Aplicada

I Congresso Nacional

de Geografia Física
OS DESAFIOS DA GEOGRAFIA FÍSICA NA FRONTEIRA DO CONHECIMENTO

Instituto de Geociências - Unicamp

Campinas - SP

28 de Junho à 02 de Julho de 2017

Desta forma, o interesse da sociedade pelo entendimento do climaproporcionou o desenvolvimento de equipamentose ferramentas capazes de obter informações necessárias para tal entendimento. Entender o comportamento climático de um lugar fornece auxílio na tomada de decisões, nas gestões dos setores socioeconômico e ambiental, tais como planejamento agrícola, recursos hídricos, turismo, entre outras, visando o bem-estar social.

Dentro dos estudos de climatologia existem diversas escalas (macro, meso, microescala) a serem trabalhadas, mas para a compreensão da realidade climática de um lugar é necessário trabalhar na escala microclimática por meio dos dados dosprincipais elementos do clima coletados em estações climatológicas ou meteorológicas na superfície distribuídos ao longo do território, tais como a radiação, a temperatura e a umidade relativa do ar, a evaporação, a precipitação, a pressão atmosférica, entre outros.

Estes equipamentos foram sendo aperfeiçoadas ao longo dos séculos, culminando nas modernas estações meteorológicas automáticas de alta precisão, que são amplamente utilizadas atualmente. O problema destas tecnologias empregadas nas estações meteorológicas automáticas é o seu alto custo, que acaba desencorajando o uso em aplicações diversas, como agricultura, acadêmico, pedagógico e turística, prejudicando assim a compreensão da relação de fatores inerentes a cada atividade.

O Arduino é um hardware criado em 2005 por um grupo de pesquisadores do Interaction Design InstituteIvrea (IDII), na Itália, com o objetivo de desenvolver um equipamentode baixo custo funcional e fácil de programar, dinamizando e viabilizando estudos nas mais diversas áreas do conhecimento. Além disso foi adotado o conceito de hardware livre, o que significa que qualquer indivíduo pode personalizar o dispositivo da maneira que lhe for conveniente.

Assim, foi criada uma placa de circuitos composta por um microcontrolador Atmel, conexões de entrada e saída, tudo programado via IDE (IntegratedDevelopmentEnvironment), ou Ambiente de Desenvolvimento Integrado, utilizando a linguagem de programação $\mathrm{C} / \mathrm{C}++$.

Tendo em vista esta problemática, o objetivo do trabalho foi comparar um protótipo de pluviômetro de baixo custoconstruído com a plataforma de prototipagem Arduino com dois pluviômetros, um convencional e um automático, da estação climatológica do Centro de Recursos Hídricos Estudos Ambientais (CRHEA), localizado em Itirapina, SP.

O período escolhido foi do dia 21 a 31de janeiro de 2017, devido aos altos acumulados pluviométricos registrados neste mês, especificamente duranteumepisódio de uma Zona de Convergência do Atlântico Sul (ZCAS).Segundo Quadros et al. (2012), a ZCAS é um 


\section{OS DESAFIOS DA GEOGRAFIA FÍSICA NA FRONTEIRA DO CONHECIMENTO}

Instituto de Geociências - Unicamp

Campinas - SP

28 de Junho à 02 de Julho de 2017

fenômeno meteorológico caracterizado pela persistência de uma faixa de nebulosidade orientada no sentido noroeste-sudeste (NW-SE), que se estende desde do centro sul da Amazônia, regiões Centro-Oeste e Sudeste, prolongando-se até sudoeste do Oceano Atlânticoe, assim, trazendo umidade nos trópicos e provocando altos totais pluviométricos na América do Sul.

\section{Área de Estudo}

O estudo foi realizado na Estação Climatológica localizada nas coordenadas 22 $10^{\prime} 12^{\prime \prime}$ (S) e 4753'55" (W), numa altitude de 737m, no Centro de Recursos Hídricos e Estudos Ambientais (CRHEA), pertencente à Escola de Engenharia de São Carlos, Universidade de São Paulo (EESC/USP) no município de Itirapina-SP (Figura 1).

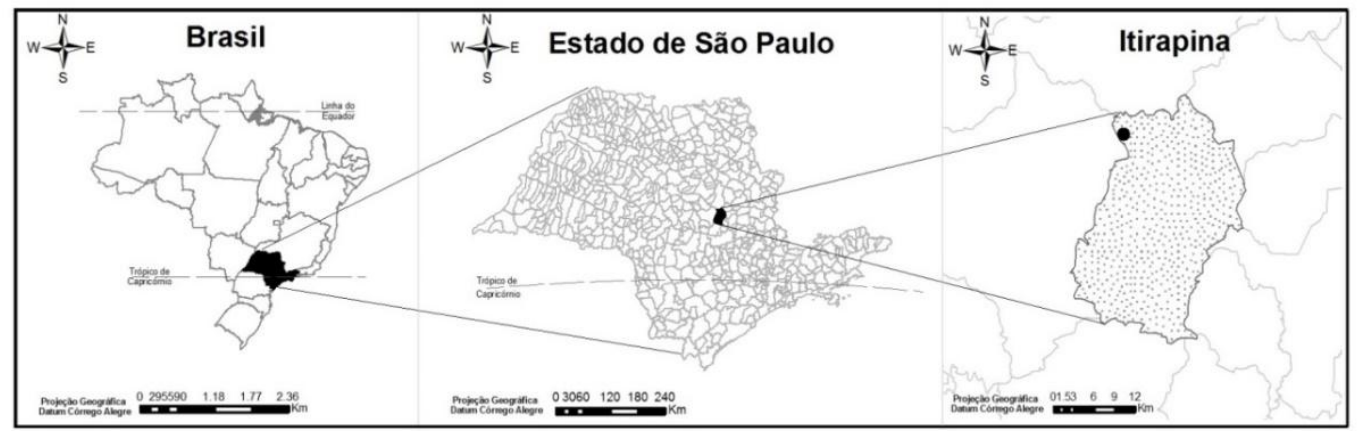

Figura 1 - Localização da Área de Estudo. Estação Climatológica do CRHEA-USP.

O clima na área de estudo é influenciado pela atuação dinâmica das massas equatoriais, tropicais e polares, apresentando as condições típicas de climas tropicais de altitudes, com inverno seco e verão chuvoso (MONTEIRO, 1973). Assim, os totais pluviométricos na região de Itirapina-SP (Figura 2) são bem definidos pela sua sazonalidade, ou seja, com semestres secos (outono-inverno) distribuídos pelos meses de abril a setembro e, semestres chuvosos (primavera-verão) distribuídos entre outubro a março, sendo que, o mês de janeiro sendo o mais chuvoso, devido a atuação mais frequente da configuração da Zona de Convergência do Atlântico Sul (ZCAS). 
XVII Simpósio Brasileiro

de Geografia Fisica Aplicada

I Congresso Nacional

de Geografia Física

\section{OS DESAFIOS DA GEOGRAFIA FÍSICA NA FRONTEIRA DO CONHECIMENTO}

Instituto de Geociências - Unicamp

Campinas - SP

28 de Junho à 02 de Julho de 2017

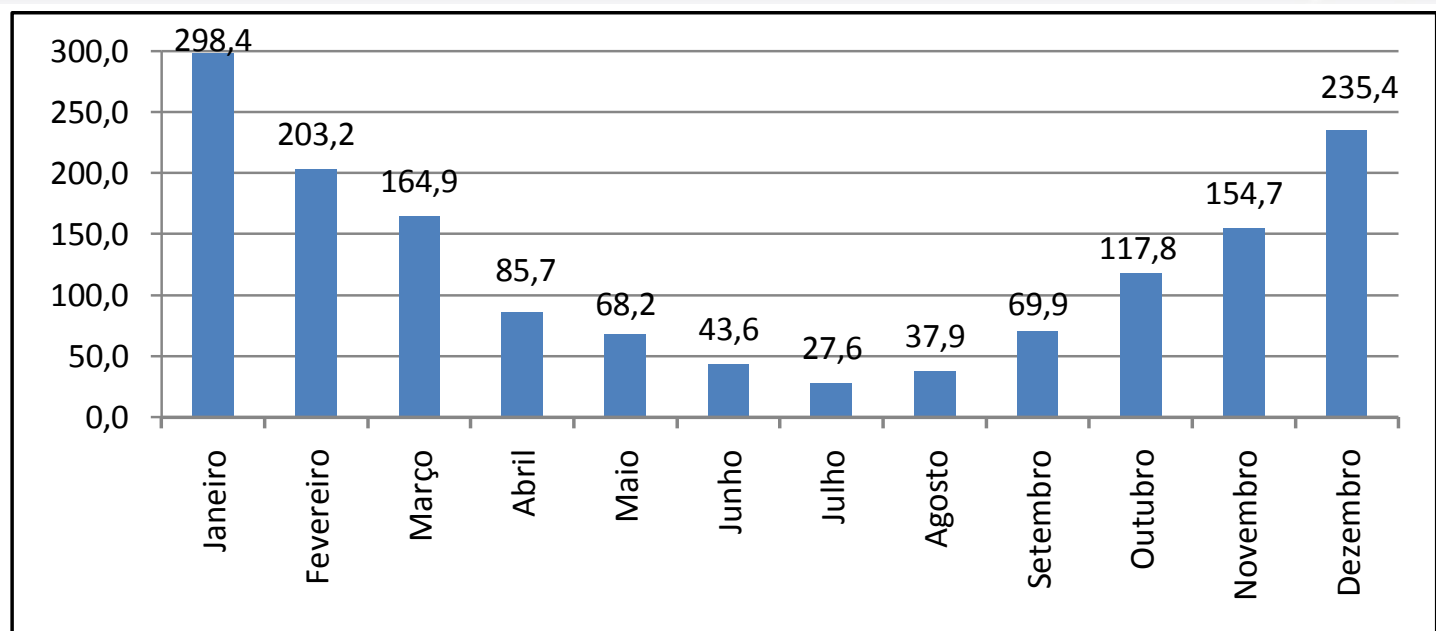

Figura 2 - Precipitação Média Mensal do Período de 1980-2014 para região de Itirapina-SP. Fonte dos dados: CRHEA-USP (2017) - Acessado em janeiro de 2017.

\section{Materiais e Métodos}

O protótipo experimental idealizado aqui é composto de um pluviômetro de alumínio estilo báscula (Figura 3) com sensor magnético tipo Reed Swicht, ligado a um Arduino UNO3 com leitor/gravador de cartão SD, que tem a função de armazenar os dados coletados. Este modelo de pluviômetro funciona direcionando a água oriundo da chuva para um coletor de perfil triangular, dividido em dois compartimentos simétricos em relação ao eixo transversal que o apoia. Apenas um dos compartimentos recebe água de cada vez. Quando o compartimento enche, o recipiente tomba para o lado dispensando o liquido e registrando uma quantidade pré-determinada. (VAREJÂO-SILVA 2000).

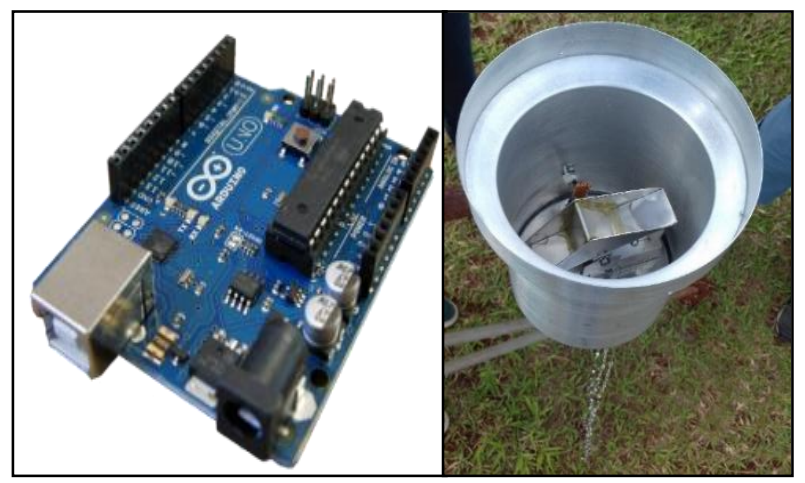

Figura 3: Arduino e o protótipo de pluviômetro

O segundoPluviômetro utilizado é um modelo TR-525M da Texas ElectronicsInc (Figura4) e funciona da mesma maneira que o Pluviômetro protótipo, através de uma báscula que mede o acumulado de precipitação. 


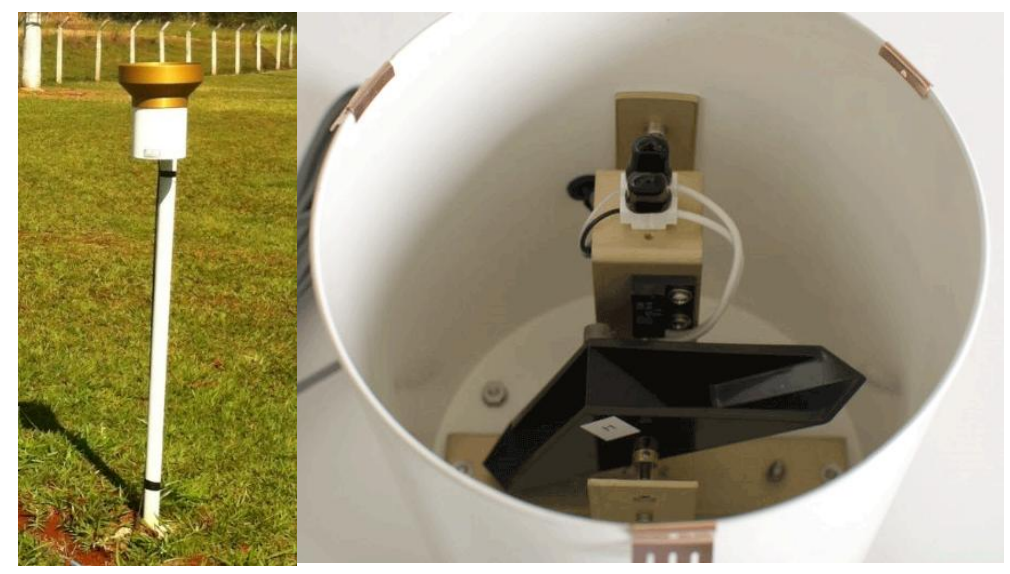

Figura 4: Pluviômetro Texas TR525M

O terceiro Pluviômetro utilizado é do tipo Villede Paris(Figura5)quesegundo Varejão-Silva (2000), é capaz de colher e quantificar toda a precipitação acumulada em 24 horas armazenando em um reservatório para medição posterior nos horários definidos pela Organização Mundial de Meteorologia (OMM).

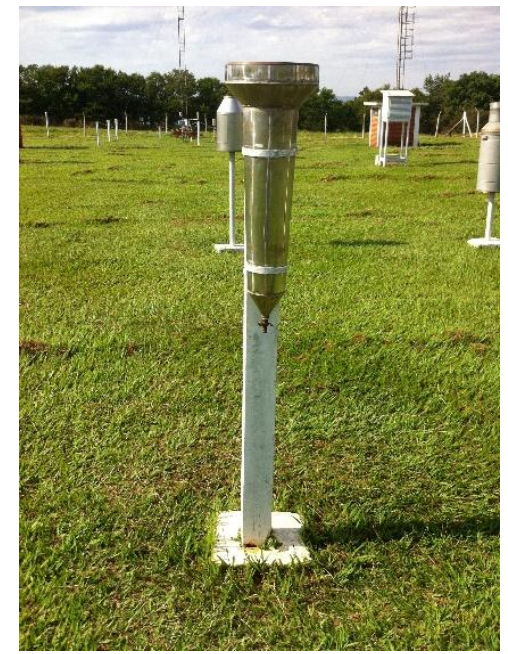

Figura 5: Pluviômetro Ville de Paris

\section{Metodologia}

Definida a área de estudo e determinado os equipamentos necessários passamos a segunda etapa da pesquisa que foi coletar os dados dos pluviômetrosreferentes ao mês de janeiro de 2017. Após isso, os dados foram divididos e analisados por meio de tempo sucessivos representativos diários.Posteriormente, foram elaboradas tabelas e gráficos com os registros pluviométricos do período, por meio do software MathWorks MATLAB R2016a, com o intuito 
OS DESAFIOS DA GEOGRAFIA FÍSICA NA FRONTEIRA DO CONHECIMENTO

Instituto de Geociências - Unicamp

Campinas - SP

28 de Junho à 02 de Julho de 2017

de facilitar a visualização e comparaçãodo comportamento pluviométrico entre 3 pluviômetros.

Após essa etapa, os dados de precipitação foram comparados por meio de duas técnicas estatísticas de correlação linear que tem a finalidade de verificar se as duas variáveis independentes estão associadas, demostradas a seguir:

\section{Coeficiente de Correlação de Pearson (r)}

Em geral, quando se deseja estudar o grau de "afinidade" entre duas séries temporais, um método bastante utilizado é o método de Pearson. Em estatística descritiva, o coeficiente de correlação de Pearson (r) - também chamado de "coeficiente de correlação produtomomento" ou simplesmente de "r de Pearson" - mede o grau da correlação entre as séries temporais entre duas variáveis quaisquer.

O método utiliza a razão dos Desvios Padrão das duas séries (série $\mathrm{X}$ e série $\mathrm{Y}$ ) da seguinte forma:

$$
\mathrm{r}=\mathrm{b}\left(\frac{\sigma_{\mathrm{X}}}{\sigma_{\mathrm{Y}}}\right)
$$

onde "b" é o coeficiente angular da reta de regressão linear cuja determinação é feita através do método dos mínimos quadrados, como mostra a equação a seguir:

$$
\mathbf{b}=\frac{\sum_{\mathrm{i}=1}^{\mathrm{n}}\left[\left(\mathrm{X}_{\mathrm{i}}-\overline{\mathrm{X}}\right)\left(\mathrm{Y}_{\mathrm{i}}-\overline{\mathrm{Y}}\right)\right]}{\sum_{\mathrm{i}=1}^{\mathrm{n}}\left(\mathrm{X}_{\mathrm{i}}-\overline{\mathrm{X}}\right)^{2}}
$$

(Erro!

\section{Indicador não definido.)}

Na Equação II, valores denotados com uma barra superior representam a média das ST, sendo $n$ o número total de valores das mesmas.

A coeficiente de Pearson tem a finalidade de mostrar o grau de "afinidade" entre duas séries temporais $\mathrm{X}$ e $\mathrm{Y}$ em função de seus Desvios Padrão, onde $-1 \leq r \leq+1$. Dessa forma, o módulo de 1 representa uma correlação perfeita (negativa ou positiva) entre as duas variáveis.

O nível de 5\% de significância estatística deve ser estabelecido antes da realização do experimento e corresponde ao risco que se corre de rejeitar uma hipótese verdadeira ou rejeitar uma hipótese falsa. A significância de um resultado também é denominada de valor 


$\begin{gathered}\text { XVII Simpósio Brasileiro } \\ \text { de Geografia Fisica Aplicada }\end{gathered}$
$\begin{aligned} & \text { I Congresso Nacional } \\ & \text { de Geografia Física }\end{aligned}$

"p" (p-value). Quando o p-value é menor ou igual a $5 \times 10^{-2}$, dizemos que a correlação é significantemente diferente de zero com $95 \%$ de confiança. Mais detalhes dos métodos de correlação podem ser encontrados em Spegel (1993) eMorenttin e Bussab (2004)

\section{Correlação de Regressão Linear: Coeficiente de Determinação $\mathbf{R}^{2}$}

A correlação linear pode ser expressa através de um gráfico de dispersão. O gráfico de dispersão é bastante útil para demonstrar a existência ou não de relações entre duas variáveis. Quanto mais alinhados estiverem os pontos à reta, maior deve ser a correlação linear entre as duas variáveis.

O coeficiente de determinação ou R-quadrado $\left(\mathrm{R}^{2}\right)$ indica o grau do ajuste linear entre duas variáveis ou o grau de dependência linear entre elas.

\section{RESULTADOS E DISCUSSÕES}

O período escolhidos para análise foi entre os dias 21 e 28 de janeiro de 2017, onde foi observada a atuação da ZCAS de maneirarepresentativa, principalmente nos dias 21 e dia 27com maiores acumulados pluviométricos dentro da análise (Figura 7).

A Figura 6 apresenta imagens de satélite do sistema EODIS da NASA dos dias 21 e 27, onde é possivel perceber a configuração típica de uma ZCAS, mostrando no destaque o estado de São Paulo.

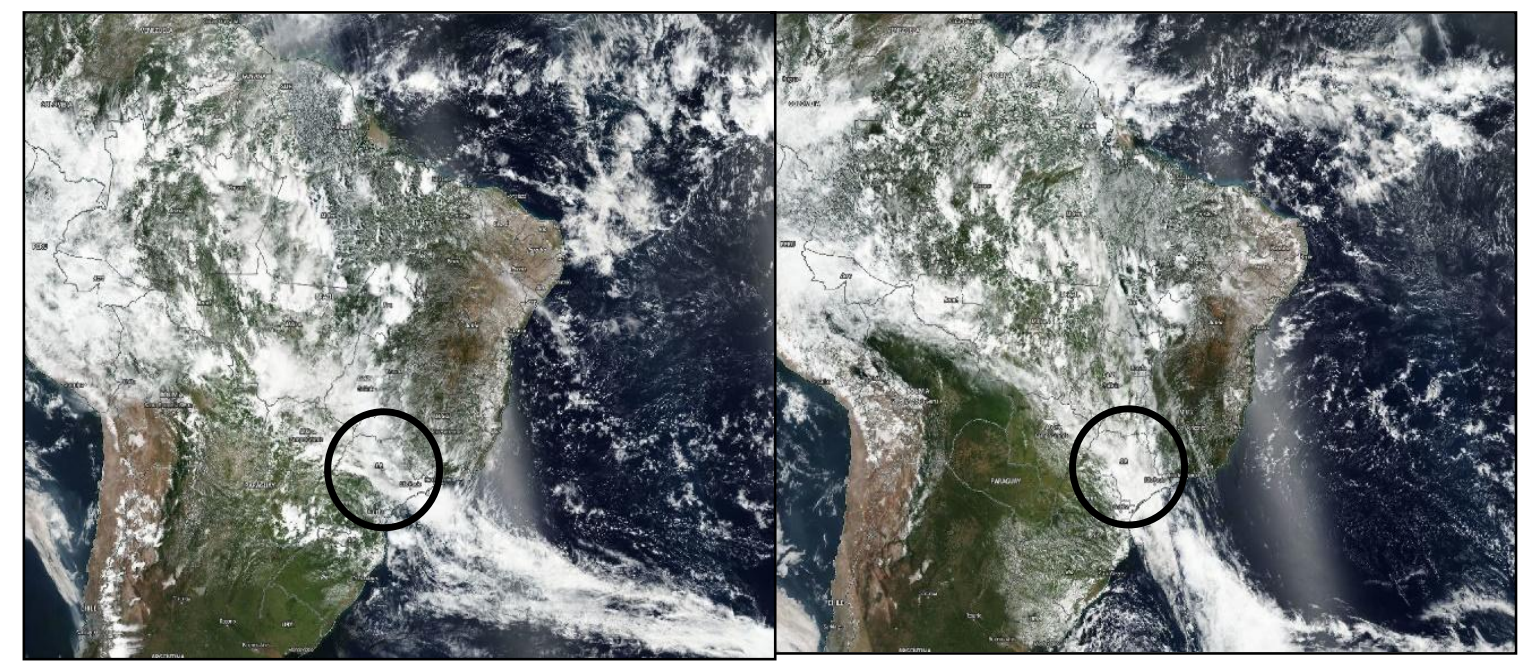

Figura 6: Atuação da ZCAS na área de estudo. Fonte: NASA/EOSDIS

A Figura 7 apresenta os registros da precipitação diária dos 10 dias (21 a 31 de Janeiro de 2017) utilizados para análise.Observa-se na figuraque os acumulados de chuvas dos 


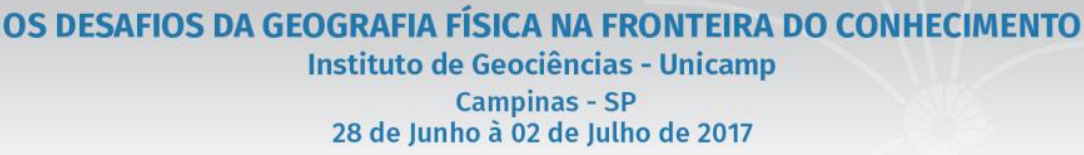

pluviômetros comportaram-se de maneira semelhante entre os eventos ocorridos, contudo, foi aplicado métodos de correlação para verificar a similaridade entre os dados.

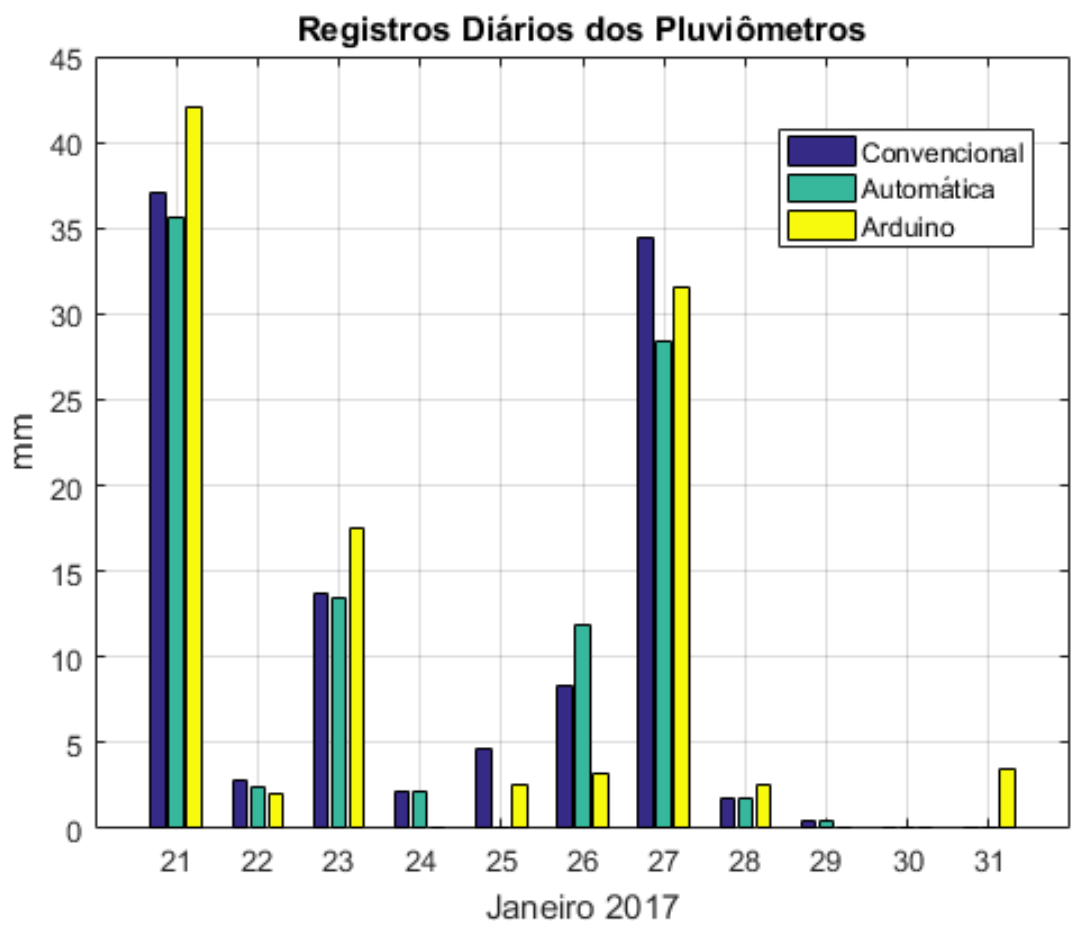

Figura 7. Registros Pluviométricos Diários dos Pluviômetros: Convencional, Automática e Protótipo Arduíno

A Tabela apresenta os valores de $\mathrm{r}$ de Pearson de o p-value do pluviômetro Automático e do protótipo Arduino em relação ao pluviômetro convencional.

Tabela I. Coeficientes de Correlação de Pearson (r) e valor de P entre os pluviômetros.

\begin{tabular}{|c|c|}
\hline Pluviômetro & Arduíno \\
\hline Automática & $r=0,96$ \\
& $p$-value $=1,3 \times 10^{-6}$ \\
\hline Convencional & $r=0,97$ \\
& $p$-value $=2,0 \times 10^{-7}$ \\
\hline
\end{tabular}

De acordo com a Tabela, os valores do coeficiente de correlação de Pearson entre Convencional-Arduino e Automática-Arduino, apresentam $r$ igual a 0,97 e 0,96, respectivamente. Isso indica um alto grau de correlação positiva entre os dados. $\mathrm{O}$ valor de $\mathrm{P}$ menos que 0,05 , para os dois casos, corrobora com a forte correlação.

A Figura 88 apresenta o gráfico de dispersão e relação linear entre os dados do pluviometro convencional e o protótipo. É possível observar que o coeficiente angular da reta é igual a 1,045 , isso indica que o arduino superestima os valores registrados pelopluviômetro convencional. 


\section{OS DESAFIOS DA GEOGRAFIA FÍSICA NA FRONTEIRA DO CONHECIMENTO \\ Instituto de Geociências - Unicamp \\ Campinas - SP \\ 28 de Junho à 02 de Julho de 2017}

Por outro lado, assim como a correlação de Pearson, o coeficiente de determinação iqual a 0,956 indica um alto grau de ajuste linear entre os dados, ou seja, um elevado grau de semelhança.

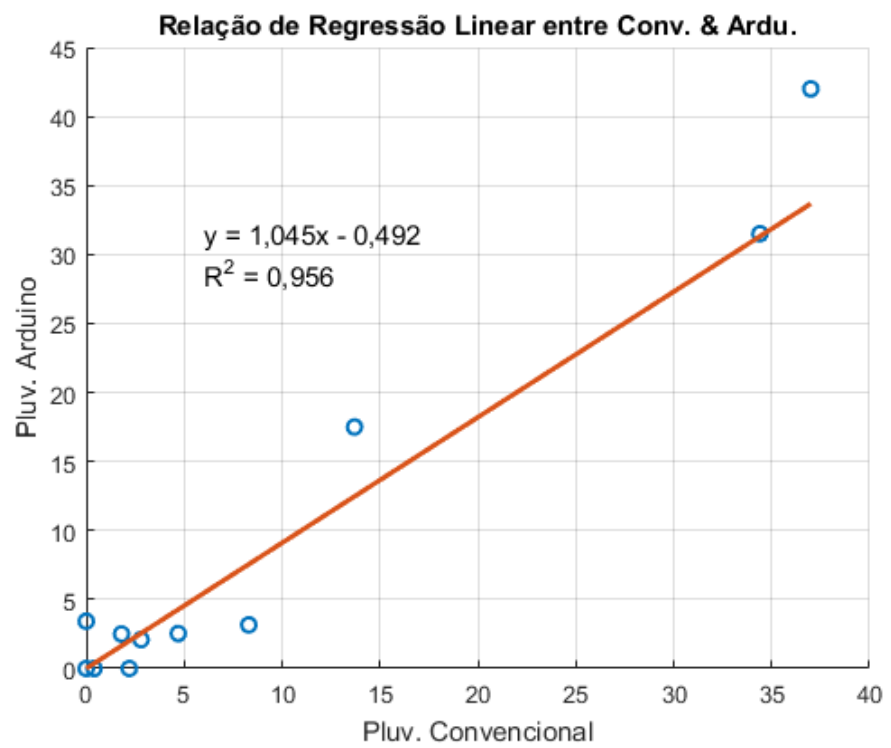

Figura 8. Dispersão dos Dados Pluv.Convencional \&Arduíno, Equação da reta e R-quadrado.

A Erro! Fonte de referência não encontrada.9 apresenta o gráfico de dispersão e relação linear entre os dados do pluviometro automático e do protótipo arduíno. É possível observar que o coeficiente angular da reta é igual a 1,119, indicando que a estação protótipo com arduíno superestima os valores registrados pelo pluviômetro automático.

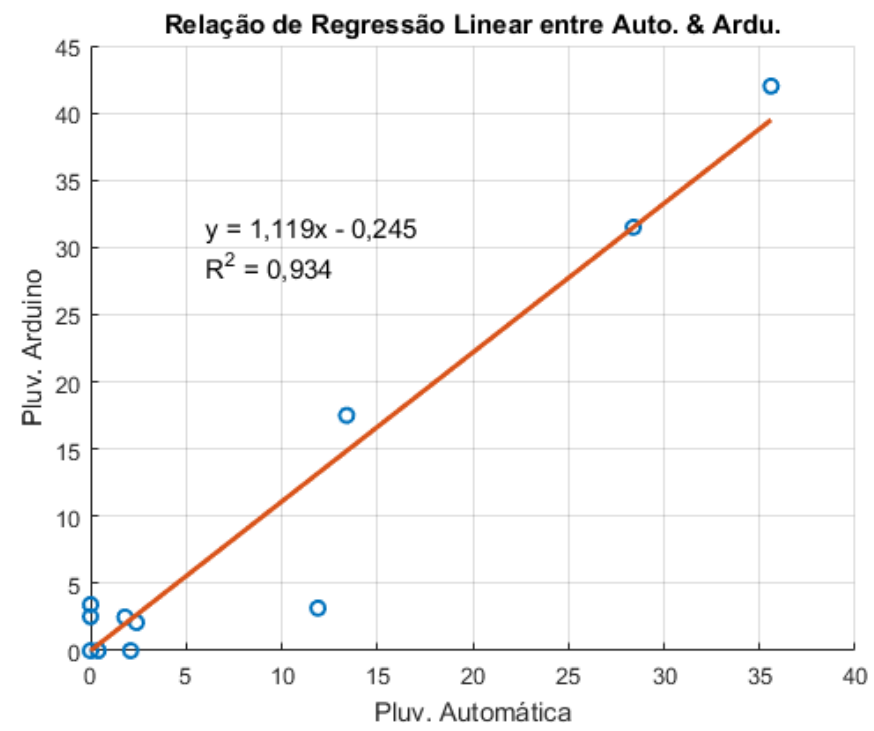

Figura 9. Dispersão dos Dados dos Pluv.Automática\&Arduíno, Equação da reta e R-quadrado 
OS DESAFIOS DA GEOGRAFIA FÍSICA NA FRONTEIRA DO CONHECIMENTO Instituto de Geociências - Unicamp Campinas - SP

28 de Junho à 02 de Julho de 2017

Por outro lado, assim como a correlação de Pearson, o coeficiente de determinação igual a 0,934 indica um alto grau de ajuste linear entre os dados, ou seja, um elevado grau de semelhança.

Após isso, aTabela apresenta a precipitação total no período de observação selecionado para o estudo. Percebe-se que a estação protótipo Arduino alcançou um valor total mais próxima a estação convencional em relação do pluviômetro automático.

Tabela II. Altura da Precipitação de cada estação de 21 a 31 de janeiro de 2017.

\begin{tabular}{|l|c|}
\hline Pluviômetro & Total (mm) \\
\hline Convencional & 105,3 \\
\hline Automático & 96 \\
\hline Protótipo Arduino & 104,7 \\
\hline
\end{tabular}

Cabe destacar que, apesar do valor da altura da precipitação do pluviómetro do arduino estar mais próximo à convencional do que o automático, os testes de correlação estatística indicam que o comportamento da estacao automática na sequencia das observações estão mais similares com a convencional do que a o protótipo arduino.

Isso de fato pode estar relacionado a oscilações do pluviômetro da placa controladora Arduino, ou a limitações na acurácia e precisão do sensor pluviométrico à variações na intensidade de precipitação.

Apesar destas oscilações, os testes estatísticos mostraram que o elevado grau de semelhança nos registros pluviométricos do arduino em relação ao pluviometro convencional e dopluviômetro automatico. Isso indica a viabilidade do uso do protótipo de baixo custo arduino para monitoramento da precipitação.

\section{CONCLUSÃO}

A obtenção de dados meteorológicos e climatológicos mostra-se, ao longo do tempo, alicerçada por meio de novas tecnologias a fim de maximizar a eficiência na coleta dos dados, bem como deve propor a redução dos custos para sua implantação, uma vez que tais dados são de grande valia para o planejamento agrícola e urbano, além de representar a base de muitos estudos em Climatologia. Nesse sentido, deve-se ressaltar a questão dos custos 
OS DESAFIOS DA GEOGRAFIA FÍSICA NA FRONTEIRA DO CONHECIMENTO

Instituto de Geociências - Unicamp

Campinas - SP

28 de Junho à 02 de Julho de 2017

envolvidos na montagem do modelo proposto, o qual possui uma diferença significativa em relação a uma estação meteorológica automática convencional do mercado. Diante disso, as principais contribuições desse trabalhose associam ao desenvolvimento da instrumentação meteorológica alternativa aos métodos convencionais de medição e de coleta de dados meteorológicos e ao avanço na capacidade de monitoramento do tempo. Identificou-se ainda que os valores captados pelopluviômetroexperimental de baixo custo são confiáveis e que os dados deixam bem claro a viabilidade do equipamento para fins didáticos, científicos e/ou profissionais. Sendo assim, a montagem de tais equipamentos mostrou-se viável para a obtenção (coleta) e organização dos dados meteorológicos, contudo, para estudos futuros, aponta-se a importância para testes que comprovem a eficácia e a eficiência de futuros protótipos de estações meteorológicas ou climatológicas de baixo custo em operação por meio de testes de validação.

\section{Agradecimentos}

Ao CNPQ e à CAPES pelo fomento ao desenvolvimento da pesquisa. À Estação Climatológica do (CRHEA). À Escola de Engenharia de São Carlos (CRHEA/EESC/USP).

\section{BIBLIOGRAFIA}

ARDUINO. Disponível em: <https://www.arduino.cc.>. Acesso em 07 de janeiro de 2016.

ARDUINO UNO. Site oficial do Arduino UNO. Disponível em: <http://www.arduino.cc/en/Main/ArduinoBoardUno>. Acesso em: 16 maio de 2016.

QUADROS M. F. L. et al. Análise climatológica da precipitação e do transporte de umidade na região da ZCAS através da nova geração de reanálises. Revista Brasileira de Meteorologia, v.27, p.152$162,2012$.

MONTEIRO, C. A. F. Dinâmica climática e as chuvas no estado de São Paulo. Estudo geográfico sob forma de atlas. São Paulo: IG/USP, 1973.

M. MCROBERTS, Arduino Básico (Novatec, São Paulo, 2011).

MORENTTIN, P. A.; BUSSAB, W O. Estatística Básica, São Paulo: Editora Atlas, 2004.

SPEGEL, Murray R. Estatística, 3. Ed.; tradução e revisão técnica Pedro Consentino - São Paulo: Pearson Makron Books, 1993.

VAREJÃO-SILVA, M. A. Meteorologia e climatologia. Brasília: INMET; Stilo, 2000.

WMO: World Meteorological Organization. Guide to Meteorological Instruments and Methods of Observation. Ed 8, 2008. 
Fonte Financiadora: CNPQ 